\title{
Effective Singlet Oxygen Sensitizers Based on the Phenazine Skeleton as Efficient Light Absorbers in Dye Photoinitiating Systems for Radical Polymerization of Acrylates
}

\author{
Ilona Pyszka *D, Zdzisław Kucybała and Beata Jędrzejewska *(D) \\ Faculty of Chemical Technology and Engineering, UTP University of Science and Technology, \\ 85-326 Bydgoszcz, Poland; kucybala@utp.edu.pl \\ * Correspondence: Ilona.Pyszka@utp.edu.pl (I.P.); beata@utp.edu.pl (B.J.); Tel.: +48-52-374-9039 (I.P.); \\ $+48-52-374-9046$ (B.J.)
}

Citation: Pyszka, I.; Kucybała, Z.; Jedrzejewska, B. Effective Singlet Oxygen Sensitizers Based on the Phenazine Skeleton as Efficient Light Absorbers in Dye Photoinitiating Systems for Radical Polymerization of Acrylates. Materials 2021, 14, 3085. https://doi.org/10.3390/ma14113085

Academic Editor: Dario Pasini

Received: 26 April 2021

Accepted: 31 May 2021

Published: 4 June 2021

Publisher's Note: MDPI stays neutral with regard to jurisdictional claims in published maps and institutional affiliations.

Copyright: (c) 2021 by the authors. Licensee MDPI, Basel, Switzerland. This article is an open access article distributed under the terms and conditions of the Creative Commons Attribution (CC BY) license (https:/ / creativecommons.org/licenses/by/ $4.0 /)$.

\begin{abstract}
A series of dyes based on the phenazine skeleton were synthesized. They differed in the number of conjugated double bonds, the arrangement of aromatic rings (linear and/or angular system), as well as the number and position of nitrogen atoms in the molecule. These compounds were investigated as potential singlet oxygen sensitizers and visible light absorbers in dye photoinitiating systems for radical polymerization. The quantum yield of the singlet oxygen formation was determined by the comparative method based on the ${ }^{1} \mathrm{H}$ NMR spectra recorded for the tested dyes in the presence of 2,3-diphenyl-p-dioxene before and after irradiation. The quantum yield of the triplet state formation was estimated based on the transient absorption spectra recorded using the nanosecond flash photolysis technique. The effectiveness of the dye photoinitiating system was characterized by the initial rate of trimethylolpropane triacrylate (TMPTA) polymerization. In the investigated photoinitiating systems, the sensitizer was an electron acceptor, whereas the co-initiator was an electron donor. The effectiveness of TMPTA photoinitiated polymerization clearly depended on the arrangement of aromatic rings and the number of nitrogen atoms in the modified phenazine structure as well as the quantum yield of the triplet state formation of the photosensitizer in the visible light region.
\end{abstract}

Keywords: phenazine derivatives; sensitizers; singlet oxygen; dye photoinitiating systems; radical polymerization

\section{Introduction}

Oxygen is the most abundant element on Earth and is involved in many chemical and physical processes. Alchemists called it the "food of life" since it is necessary for life. Despite its huge positive role, oxygen can also destroy cell structures, which, in turn, contributes to the aging of organisms and the development of cancer. Changes in the properties of oxygen and its ability to initiate a number of processes are conditioned by the presence of light. Because of the interaction of electromagnetic radiation with oxygen, reactive oxygen species (ROS), widely described in literature, may be formed [1]. They are highly energetic, and the excess energy is responsible for their high reactivity. One such form is singlet oxygen.

In the ground state, the oxygen molecule has two unpaired electrons having their spins parallel and occupying perpendicular anti-bonding orbitals $\pi$, so it is in the triplet form $\left({ }^{3} \mathrm{O}_{2}\right)$. Thus, the $\mathrm{O}_{2}$ molecule is paramagnetic - the spin quantum number is 1 . When the molecule gains energy upon excitation, the electron spins are paired, and the electron configuration of the oxygen molecule changes from a triplet to a singlet ${ }^{1} \mathrm{O}_{2}$. Thus, in the excited state, the spin quantum number is 0 . Such a system of energy levels distinguishes the oxygen molecule from the vast majority of organic compounds for which the electronic 
ground state is the singlet state $S_{0}$, whereas the lowest excited energy state is the triplet state $\mathrm{T}_{1}[2-4]$.

This chemically useful singlet oxygen form can be prepared by two main methods, i.e., irradiation of the ${ }^{3} \mathrm{O}_{2}$ form and chemical synthesis. The latter method produces the singlet oxygen as one of the products of a chemical reaction. The following examples can be given: (i) the reaction of hydrogen peroxide with sodium chlorate (I) [5-7], (ii) the decomposition of some peroxides [8-10], and (iii) the decomposition of adducts of organophosphorus compounds and ozone [11,12]. The other way is to produce singlet oxygen by an atmospheric discharge $[13,14]$. In nature, singlet oxygen is commonly formed from water during photosynthesis, using the energy of sunlight [15]. It is also produced in the troposphere by the photolysis of ozone by light of short wavelength [16] and by the immune system as a source of active oxygen [17].

However, a more interesting way to generate singlet oxygen is a photochemical process based on an excitation of triplet oxygen with ultraviolet light in the presence of a sensitizing dye. In that case, oxygen molecule takes energy from the sensitizer being in the triplet excited state. A singlet oxygen sensitizer can be any compound that forms a triplet state and fulfils the following conditions:

1. It does not react with oxygen, i.e., it does not undergo auto-oxidation [18,19];

2. It has a high molar absorption coefficient at the excitation wavelength and the appropriate spectral characteristics enabling selective excitation of the sensitizer, while limiting the excitation of other molecules present in the solution;

3. It has a low triplet state energy [20].

The above conditions are met by a number of organic compounds that are effective singlet oxygen sensitizers, e.g., erythrosine, methylene blue, chlorophyll, hematoporphyrin, rose bengal, perinaftenone, acridine, and others [21-23].

Singlet oxygen sensitizers usually operate in the same phase in which the photooxidation is performed. In that case, the sensitization reaction is carried out in solution. However, a number of heterogeneous sensitizers have now been developed. Their use allows for photooxidation without side effects. There are several ways to prepare heterogeneous sensitizers. One of them is using a polymeric carrier (e.g., chloromethylated polystyrene beads or modified silica gel) to which the sensitizer is chemically attached [24,25].

Upon excitation the sensitizer molecule undergoes a change from the singlet ground state $S\left(S_{0}\right)$ to the singlet excited state ${ }^{*} S\left(S_{1}\right)$.

$$
\mathrm{S}\left(\mathrm{S}_{0}\right)+\mathrm{h} v \rightarrow{ }^{*} \mathrm{~S}\left(\mathrm{~S}_{1}\right)
$$

As a result of the energy transfer (or electron transfer) from the sensitizer molecule in its excited singlet state ${ }^{*} \mathrm{~S}\left(\mathrm{~S}_{1}\right)$ to the ground-state oxygen molecule ${ }^{3} \mathrm{O}_{2}$ through collisions, the sensitizer molecule goes to the triplet state ${ }^{*}\left(T_{1}\right)$. The singlet oxygen formed in the excited state can oxidize other compounds.

$$
{ }^{*} \mathrm{~S}\left(\mathrm{~S}_{1}\right)+{ }^{3} \mathrm{O}_{2} \rightarrow{ }^{*} \mathrm{~S}\left(\mathrm{~T}_{1}\right)+{ }^{1} \mathrm{O}_{2}\left({ }^{1} \Delta \mathrm{g}\right)
$$

Only those sensitizers with a lifetime of the $S_{1}$ excited state greater than ns will be effective in interacting with oxygen molecules. Furthermore, when the energy gap for the sensitizer is lower than the triplet-singlet energy difference for the oxygen molecule, the process described by Equation (2) is not allowed energetically. In such a case, the oxygen molecule may be a medium participating in the formation of the triplet state of the sensitizer molecule (Equation (3)) or may influence the process of deactivating the excited singlet state of the sensitizer ${ }^{*} S\left(S_{1}\right)$ to the ground state $S\left(S_{0}\right)$ (Equation (4)). Both of these processes can occur through the formation of an exciplex. Polycyclic aromatic hydrocarbons mostly undergo the processes described by Equations (3) and (4) because of the insufficient energy difference between the states $S_{1}$ and $T_{1}$.

$$
{ }^{*} \mathrm{~S}\left(\mathrm{~S}_{1}\right)+{ }^{3} \mathrm{O}_{2} \rightarrow{ }^{*} \mathrm{~S}\left(\mathrm{~T}_{1}\right)+{ }^{3} \mathrm{O}_{2}
$$




$$
{ }^{*} \mathrm{~S}\left(\mathrm{~S}_{1}\right)+{ }^{3} \mathrm{O}_{2} \rightarrow \mathrm{S}\left(\mathrm{S}_{0}\right)+{ }^{3} \mathrm{O}_{2}
$$

The most effective method of generating singlet oxygen under laboratory conditions is the triplet $\left(\mathrm{T}_{1}\right)$ quenching of the sensitizer molecule. This method plays an important role in many applications of oxygen.

The study of reactive oxygen species is crucial for several groups of scientists, including photochemists, biologists, and physiologists [2,26-30]. The search for new, efficient singlet oxygen sensitizers seems to be important because of the positive and negative role of singlet oxygen for humans. Singlet oxygen is used in medicine because it can be involved, for example, in the destruction of cancer cells [23]. In addition, photo-oxidation occurring under the influence of singlet oxygen is used to sterilize blood and surgical instruments as well as to purify water $[22,31]$. The negative effects of singlet oxygen include polymer degradation and photo-oxidation of food products [32].

In the present work, our intention was to apply dyes based on the phenazine skeleton, which effectively generated singlet oxygen, as visible light absorbers in the photoinitiating systems for radical polymerization. Such dye photoinitiators operate through a longlived triplet state, which is beneficial in terms of generating radicals through the electron transfer process. Therefore, we performed a comparative study on the quantum yield of the triplet state formation of the phenazine derivatives. We investigated the dye-sensitized photooxidation of 2,3-diphenyl-1,4-dioxene (DPD) to determine the quantum yield of singlet oxygen as it is equal to the quantum yield of triplet state formation when large excess oxygen is used. Additionally, we used a nanosecond flash photolysis technique since the analysis of transient absorption spectra allowed us to determine the quantum yield of the triplet state formation as well.

We have attempted to test phenazine derivatives as photosensitizers in radical polymerization, as new dye structures are still being sought because of the high demands placed on photoinitiators in modern applications such as dental filling materials, reprography (photoresists, printing plates, integrated circuits), laser-induced 3D curing, holographic recordings, and nanoscale micromechanics. Modifications of the photosensitizer structure were carried out by introducing heavy atoms and electron-donating or electronwithdrawing substituents to various heterocyclic rings [33-43] or by the preparation of new chemical skeletons. Our strategy for synthesis followed the modification of phenazine structure by increasing either nitrogen atoms to 3 or 4 in the dye molecule or aromatic rings in the angular and/or linear positions. Such phenazine-functionalized dyes fulfilled the requirements for photoinitiators of radical polymerization, i.e., they exhibited high molar absorption coefficients in visible light, efficiently interacted with additives (e.g., electron donors), and revealed a long-lived triplet state. Moreover, their activity in the visible light region allowed them to meet economic and environmental constraints because visible light is safer, cheaper, and more easily available than ultraviolet light; therefore, inexpensive irradiation setups like low-power light-emitting diodes (LEDs) and diode-pumped solid-state (DPSS) lasers can be used to initiate the polymerization reaction [44].

The synthesized dyes were used as a primary light absorber, which formed the photoinitiating system with a suitable co-initiator. In our study, we used commercially available [(3,4-dimethoxyphenyl)sulfanyl]acetic acid as the co-initiator.

\section{Materials and Methods}

\subsection{Reagents}

Dye sensitizers based on the phenazine skeleton (FN1-FN13) (see Table 1) were synthesized by the condensation of appropriate diamines with quinones using the method described in the literature [45-55]. The crude product was purified by recrystallization from ethyl acetate. Reagents for synthesis: 1,2-diaminobenzene and 2,3-diaminonaphthalene were purchased from Alfa Aesar Co., Ward Hill, MA, United States; 9,10-phenanthrenequinone, 1,2naphthoquinone, 9,10-diaminophenanthrene, 2,3-diaminopyridine, 4, 5-diamino-pyrimidine, 4-bromo-1,2-diaminobenzene, and 2,3-diamino-5-bromopyridine were purchased from SigmaAldrich Co, Saint Louis, MO, United States; 1,2-diammonocyclohexane and 1,10-phenanthroline- 
5,6-dione were purchased from Acros Organics Co, Pittsburgh, PA, United States; and 5-bromo2,3-diaminopyrazine was purchased from Fluorochem Co, Hadfield, UK.

Table 1. Structures, basic spectroscopic properties, and quantum yields of fluorescence for the dyes tested.

\begin{tabular}{|c|c|c|c|c|c|}
\hline Dye & Structure & $\lambda_{\text {max }}^{A b}, n m$ & $\epsilon_{\max }^{A b}, M^{-1} c^{-1}$ & $\lambda_{\text {max }}^{F l}, n m$ & $\Phi_{F l}$ \\
\hline FN1 & & $\begin{array}{l}345 \\
362\end{array}$ & $\begin{array}{c}8060 \\
10,400\end{array}$ & 383.0 & 0.110 \\
\hline FN2 & & $\begin{array}{l}375 \\
395\end{array}$ & $\begin{array}{c}9700 \\
11,400\end{array}$ & 413.6 & 0.044 \\
\hline FN3 & & $\begin{array}{l}402 \\
425\end{array}$ & $\begin{array}{l}10,060 \\
13,500\end{array}$ & 532.8 & 0.045 \\
\hline FN4 & & $\begin{array}{l}392 \\
414\end{array}$ & $\begin{array}{c}9900 \\
15,900\end{array}$ & $\begin{array}{l}415.2 \\
438.4\end{array}$ & 0.027 \\
\hline FN5 & & $\begin{array}{l}392 \\
414\end{array}$ & $\begin{array}{c}9700 \\
16,300\end{array}$ & $\begin{array}{l}414.2 \\
438.0\end{array}$ & 0.049 \\
\hline FN6 & & $\begin{array}{l}386 \\
407\end{array}$ & $\begin{array}{c}9500 \\
10,900\end{array}$ & 437.8 & 0.025 \\
\hline FN7 & & $\begin{array}{l}409 \\
432\end{array}$ & $\begin{array}{l}14,000 \\
10,800\end{array}$ & 543.8 & 0.025 \\
\hline FN8 & & $\begin{array}{l}383 \\
393\end{array}$ & $\begin{array}{l}9600 \\
9620\end{array}$ & 460 & 0.045 \\
\hline FN9 & & $\begin{array}{l}382 \\
403\end{array}$ & $\begin{array}{l}20,500 \\
25,600\end{array}$ & 424.2 & 0.033 \\
\hline
\end{tabular}


Table 1. Cont.

\begin{tabular}{|c|c|c|c|c|c|}
\hline Dye & Structure & $\lambda_{\text {max }}^{A b}, n m$ & $\epsilon_{\max }^{A b}, M^{-1} \mathrm{~cm}^{-1}$ & $\lambda_{\text {max }}^{F l}, n m$ & $\Phi_{F l}$ \\
\hline FN10 & & $\begin{array}{l}390 \\
407\end{array}$ & $\begin{array}{l}15,900 \\
16,300\end{array}$ & 428 & 0.028 \\
\hline FN11 & & $\begin{array}{l}395 \\
411\end{array}$ & $\begin{array}{l}14,300 \\
15,800\end{array}$ & 445.6 & 0.042 \\
\hline FN12 & & $\begin{array}{l}360 \\
378\end{array}$ & $\begin{array}{l}14,500 \\
13,700\end{array}$ & 412.4 & 0.047 \\
\hline FN13 & & 437 & 11,490 & 477 & 0.100 \\
\hline CQ & & 472 & 40 & - & - \\
\hline
\end{tabular}

All solvents for synthesis, photochemical studies, and NMR analysis, including acetic acid, ethyl acetate, deuterated chloroform $\left(\mathrm{CDCl}_{3}\right)$, chloroform, and 1-methyl-2pyrrolidinone (MP), were purchased from Sigma-Aldrich Co, Saint Louis, MO, United States. The DC-Plastikfolien Silica gel 60 F254 thin layer chromatography plates $(0.2 \mathrm{~mm})$ were from Merck Co, Kenilworth, NJ, USA.

Camphorquinone (CQ, initiator), [(3,4-dimethoxyphenyl)sulfanyl]acetic acid (MKTFO, co-initiator), and trimethylolpropane triacrylate (TMPTA, monomer) were obtained from Sigma-Aldrich Co, Saint Louis, MO, USA.

\subsection{Synthesis}

10,11,12,13-Tetrahydrodibenzo[a,c]phenazine-FN1

1,2-diaminocyclohexane $(0.548 \mathrm{~g}, 4.8 \mathrm{mmol})$ was refluxed with 9,10-phenrenequinone $(1 \mathrm{~g}, 4.8 \mathrm{mmol})$ in glacial acetic acid $(40 \mathrm{~mL})$ for $2 \mathrm{~h}$. The compound was obtained as yellow crystals: $\mathrm{C}_{20} \mathrm{H}_{18} \mathrm{~N}_{2}, 286.38 \mathrm{~g} / \mathrm{mol}, 1.12 \mathrm{~g}$, yield $82 \%$, m.p. $174-176{ }^{\circ} \mathrm{C}$, lit. $173{ }^{\circ} \mathrm{C}$ [51].

${ }^{1} \mathrm{H} \mathrm{NMR}\left(400 \mathrm{MHz}, \mathrm{CDCl}_{3}, 8\right): 9.24-9.21(\mathrm{~d}, 1 \mathrm{H}), 8.62-8.59(\mathrm{~d}, 2 \mathrm{H}), 7.78-7.70(\mathrm{~m}, 4 \mathrm{H})$, $3.28-3.25(\mathrm{~m}, 5 \mathrm{H}), 2.02-2.08(\mathrm{~m}, 5 \mathrm{H})$

${ }^{13} \mathrm{C} \mathrm{NMR}\left(100 \mathrm{MHz}, \mathrm{CDCl}_{3}, \delta\right): 152.1,138.2,135.8,131.0,129.2,129.1,127.5,125.23$, $122.6,32.4,22.75$

Dibenzo[a,c]phenazine-FN2

1,2-diaminobenzene ( $0.519 \mathrm{~g}, 4.8 \mathrm{mmol})$ was refluxed with 9,10-phenrenequinone ( $1 \mathrm{~g}$, $4.8 \mathrm{mmol}$ ) in glacial acetic acid $(80 \mathrm{~mL})$ for $2 \mathrm{~h}$. The compound was obtained as pale, yellow crystals: $\mathrm{C}_{20} \mathrm{H}_{12} \mathrm{~N}_{2}, 280.33 \mathrm{~g} / \mathrm{mol}, 1.34$ g, yield $80 \%$, m.p. $224-225{ }^{\circ} \mathrm{C}$, lit. 224-226 ${ }^{\circ} \mathrm{C}$ [56].

${ }^{1} \mathrm{H}$ NMR $\left(400 \mathrm{MHz}, \mathrm{CDCl}_{3}, \delta\right): 9.34(\mathrm{~d}, 2 \mathrm{H}), 9,32(\mathrm{~d}, 2 \mathrm{H}), 8.50-8.48(\mathrm{~d}, 2 \mathrm{H}), 8.27-8.24$ $(\mathrm{m}, 2 \mathrm{H}), 7.870-7.65(\mathrm{~m}, 6 \mathrm{H})$ 
${ }^{13} \mathrm{C}$ NMR $\left(100 \mathrm{MHz}, \mathrm{CDCl}_{3}, \delta\right): 141.8,141.3,132.0,130.7,130.2,129.3,128.9,128.0$, $126.5,122,9$

Tribenzo[a,c,i]phenazine-FN3

2,3-diaminonaphthalene $(0.76 \mathrm{~g}, 4.8 \mathrm{mmol})$ was refluxed with 9,10-phenrenequinone (1 $\mathrm{g}$, $4.8 \mathrm{mmol})$ in glacial acetic acid $(100 \mathrm{~mL})$ for $2 \mathrm{~h}$. The compound was obtained as yellow crystals: $\mathrm{C}_{24} \mathrm{H}_{14} \mathrm{~N}_{2}, 330.39 \mathrm{~g} / \mathrm{mol}, 1.36$ g, yield $86 \%$, m.p. $292-293{ }^{\circ} \mathrm{C}$, lit. 291-293 ${ }^{\circ} \mathrm{C}$ [57].

${ }^{1} \mathrm{H}$ NMR $\left(400 \mathrm{MHz}, \mathrm{CDCl}_{3}, \delta\right): 9.38-9.36(\mathrm{~d}, 2 \mathrm{H}), 8.88(\mathrm{~s}, 2 \mathrm{H}), 8,47-8.45(\mathrm{~d}, 2 \mathrm{H})$, 8.14-8.11 (m, 4H), 7.76-7.51 (m, 4H)

Tribenzo[a,c,h]phenazine- $F N 4$

1,2-naphthoquinone ( $0.76 \mathrm{~g}, 4.8 \mathrm{mmol})$ was refluxed with 9,10-phenrenequinone ( $1 \mathrm{~g}$, $4.8 \mathrm{mmol})$ in glacial acetic acid $(150 \mathrm{~mL})$ for $1 \mathrm{~h}$. The compound was obtained as yellow crystals: $\mathrm{C}_{24} \mathrm{H}_{14} \mathrm{~N}_{2}, 330.39 \mathrm{~g} / \mathrm{mol}, 1.0$ g, yield $63 \%$, m.p. $257-258{ }^{\circ} \mathrm{C}$, lit. $278-279{ }^{\circ} \mathrm{C}$ [58].

${ }^{1} \mathrm{H}$ NMR $\left(400 \mathrm{MHz}, \mathrm{CDCl}_{3}, 8\right): 9.78(\mathrm{~d}, 1 \mathrm{H}), 9.62(\mathrm{~d}, 2 \mathrm{H}), 8.93(\mathrm{~d}, 1 \mathrm{H}), 8.69(\mathrm{~m}, 2 \mathrm{H})$, 8.47-8.44 (m, 2H), $8.23(\mathrm{~d}, 2 \mathrm{H}), 7.93-7.86(\mathrm{~m}, 4 \mathrm{H})$

Tetrabenzo[a,c,h,i]phenazine-FN5

9,10-diaminophenanthrene $(1.0 \mathrm{~g}, 4.8 \mathrm{mmol})$ was refluxed with 9,10-phenrenequinone $(1 \mathrm{~g}, 4.8 \mathrm{mmol})$ in glacial acetic acid $(150 \mathrm{~mL})$ for $2 \mathrm{~h}$. The compound was obtained as yellow crystals: $\mathrm{C}_{28} \mathrm{H}_{16} \mathrm{~N}_{2}, 380.45 \mathrm{~g} / \mathrm{mol}, 1.1 \mathrm{~g}$, yield $60 \%$, m.p., lit. $462{ }^{\circ} \mathrm{C}$ [59].

${ }^{1}$ HNMR $\left(400 \mathrm{MHz}\right.$, DMSO- $\left.d_{6}, \delta\right): 8.33-8.31(\mathrm{~d}, 4 \mathrm{H}), 8.05(\mathrm{~d}, 2 \mathrm{H}), 8.03(\mathrm{~d}, 2 \mathrm{H}), 7.82-7.77$ $(\mathrm{d}, 5 \mathrm{H}), 7.56-7.53(\mathrm{~m}, 3 \mathrm{H})$

Benzo[a]phenazine-FN6

1,2-diaminobenzene $(0.68 \mathrm{~g}, 6.3 \mathrm{mmol})$ was refluxed with 1,2-naphthoquinone ( $1 \mathrm{~g}$, $6.3 \mathrm{mmol})$ in glacial acetic acid $(100 \mathrm{~mL})$ for $2 \mathrm{~h}$. The compound was obtained as yellow crystals: $\mathrm{C}_{16} \mathrm{H}_{10} \mathrm{~N}_{2}, 230.27 \mathrm{~g} / \mathrm{mol}, 0.94$ g, yield $65 \%$, m.p. $230-232^{\circ} \mathrm{C}$, lit. $230-233^{\circ} \mathrm{C}$ [52].

${ }^{1} \mathrm{HNMR}\left(400 \mathrm{MHz}, \mathrm{CDCl}_{3}, \delta\right): 9.65(1 \mathrm{H}, \mathrm{d}), 8.50(1 \mathrm{H}, \mathrm{d}), 8.37(1 \mathrm{H}, \mathrm{d}), 8.23(1 \mathrm{H}, \mathrm{d})$, 7.99-7.60 (m, 6H)

${ }^{13} \mathrm{C}$ NMR $\left(100 \mathrm{MHz}, \mathrm{CDCl}_{3}, 8\right): 142.9,142.5,132.9,131.1,131.0,130.6,130.3,129.9$, $128.6,128.2,127.4,125.80$

Dibenzo[a,i]phenazine-FN7

2,3-diaminonaphthalene $(1.0 \mathrm{~g}, 6.3 \mathrm{mmol})$ was refluxed with 1,2-naphthoquinone $(1 \mathrm{~g}$, $6.3 \mathrm{mmol})$ in glacial acetic acid $(100 \mathrm{~mL})$ for $2 \mathrm{~h}$. The compound was obtained as yellow crystals: $\mathrm{C}_{20} \mathrm{H}_{12} \mathrm{~N}_{2}, 280.33 \mathrm{~g} / \mathrm{mol}, 0.94 \mathrm{~g}$, yield $87 \%$, m.p. $247-248{ }^{\circ} \mathrm{C}$, lit. $247^{\circ} \mathrm{C}$ [60].

${ }^{1} \mathrm{HNMR}\left(400 \mathrm{MHz}, \mathrm{CDCl}_{3}, \delta\right): 9.32(\mathrm{~d}, 1 \mathrm{H}), 9.03(\mathrm{~s}, 1 \mathrm{H}), 8.94(\mathrm{~s}, 1 \mathrm{H}), 8.15(\mathrm{~m}, 3 \mathrm{H}), 8.03$ $(\mathrm{d}, 1 \mathrm{H}), 7.86-7.77(\mathrm{~m}, 3 \mathrm{H}), 7.61-7.59(\mathrm{~m}, 2 \mathrm{H})$

${ }^{13} \mathrm{C}$ NMR $\left(100 \mathrm{MHz}, \mathrm{CDCl}_{3}, 8\right): 143.9,138.7,136.8,134.7,134.2,132.8,130.8,130.5$, 129.0, 128.8, 128.5, 128.4, 128.1, 127.7, 127.2, 125.6, 124.6, 124.4

Dibenzo[f, h]pyrido[2, 3-b]quinoxaline-FN8

1,2-diaminopyridine $(0.53 \mathrm{~g}, 4.8 \mathrm{mmol})$ was refluxed with 9,10-phenanthrenequinone $(1 \mathrm{~g}, 4.8 \mathrm{mmol})$ in glacial acetic acid $(80 \mathrm{~mL})$ for $2 \mathrm{~h}$. The compound was obtained as yellow crystals: $\mathrm{C}_{19} \mathrm{H}_{11} \mathrm{~N}_{3}, 281.32 \mathrm{~g} / \mathrm{mol}, 1.1 \mathrm{~g}$, yield $81 \%$, m.p. $218-219{ }^{\circ} \mathrm{C}$, lit. $217-219{ }^{\circ} \mathrm{C}$ [48,49].

${ }^{1} \mathrm{HNMR}\left(400 \mathrm{MHz}, \mathrm{CDCl}_{3}, 8\right): 9.52-9.49(\mathrm{~d}, 1 \mathrm{H}), 9.31-9.27(\mathrm{~m}, 2 \mathrm{H}), 8.66-8.64(\mathrm{~d}, 1 \mathrm{H})$, 8.52-8.50 (d, 2H), 7.84-7.68 (m, 5H)

${ }^{13} \mathrm{C}$ NMR $\left(100 \mathrm{MHz}, \mathrm{CDCl}_{3}, \delta\right): 154.4,149.8,145.0,143.6,138.3,137.3,132.5,132.3$, $131.3,130.8,129.7,129.5,128.1,128.0,127.3,126.4,124.8,123.0,122.8$

11-Bromodibenzo[a, c]phenazine-FN9

4-bromo-1,2-diaminobenzene $(0.898 \mathrm{~g}, 4.8 \mathrm{mmol})$ was refluxed with 9,10-phenanthrenequinone $(1 \mathrm{~g}, 4.8 \mathrm{mmol})$ in glacial acetic acid $(80 \mathrm{~mL})$ for $30 \mathrm{~min}$. The compound was obtained as yellow crystals: $\mathrm{C}_{20} \mathrm{H}_{11} \mathrm{BrN}_{2}, 359.23 \mathrm{~g} / \mathrm{mol}, 1.24 \mathrm{~g}$, yield $72 \%$, m.p. $274-27{ }^{\circ} \mathrm{C}$, lit. $274-276{ }^{\circ} \mathrm{C}$ [46].

${ }^{1} \mathrm{HNMR}\left(400 \mathrm{MHz}, \mathrm{CDCl}_{3}, \delta\right): 9.38-9.35(\mathrm{~m}, 2 \mathrm{H}), 8,59-8.57(\mathrm{~d}, 2 \mathrm{H}), 8.53(\mathrm{~d}, 1 \mathrm{H})$, 8.21-8.19 (d, 1H), 7.94-7.91 (m, 1H), 7.85-7.74 (m, 4H)

${ }^{13} \mathrm{C} \mathrm{NMR}\left(100 \mathrm{MHz}, \mathrm{CDCl}_{3}, 8\right): 133.7,132.3,132.26,131.2,131.0,130.9,130.2,128.2$, $128.1,126.6,126.6,123.0,123.0$

12-Bromo-dibenzo[f, h]pyrido[2, 3-b]quinoxaline-FN10 
5-bromo-1,2-diaminobenzene $(0.898 \mathrm{~g}$, $4.8 \mathrm{mmol})$ was refluxed with 9,10-phenanthrenequinone $(1 \mathrm{~g}, 4.8 \mathrm{mmol})$ in glacial acetic acid $(80 \mathrm{~mL})$ for $2 \mathrm{~h}$. The compound was obtained as yellow crystals: $\mathrm{C}_{19} \mathrm{H}_{10} \mathrm{BrN}_{3}, 360.21 \mathrm{~g} / \mathrm{mol}, 1.42 \mathrm{~g}$, yield $77 \%$, m.p. $235-238{ }^{\circ} \mathrm{C}$, lit. 235-238 ${ }^{\circ} \mathrm{C}[49,57]$.

${ }^{1} \mathrm{HNMR}\left(400 \mathrm{MHz}, \mathrm{CDCl}_{3}, \delta\right): 9.43-9.41(\mathrm{~d}, 1 \mathrm{H}), 9.25(\mathrm{~s}, 1 \mathrm{H}), 9.20-9.18(\mathrm{~d}, 1 \mathrm{H}), 8.77$ (s, $1 \mathrm{H}), 8.52-8.50(\mathrm{~d}, 2 \mathrm{H}), 7.85-7.68(\mathrm{~m}, 4 \mathrm{H})$

${ }^{13} \mathrm{C}$ NMR (100 MHz, $\left.\mathrm{CDCl}_{3}, \delta\right): 155.3,148.0,145.1,144.1,139.5,137.4,132.5,132.5$, $131.4,131.2,129.4,129.1,128.3,128.1,127.4,126.6,123.0,122.9,120.5$

Dibenzo[f, h]pyrazino[2,3-b]quinoxaline-FN11

5-bromo-2,3-diaminopyrazine $(0.9 \mathrm{~g}, 4.8 \mathrm{mmol})$ was refluxed with 9,10-phenanthrenequinone $(1 \mathrm{~g}, 4.8 \mathrm{mmol})$ in glacial acetic acid $(80 \mathrm{~mL})$ for $2 \mathrm{~h}$. The compound was obtained as yellow crystals: $\mathrm{C}_{18} \mathrm{H}_{9} \mathrm{BrN}_{4}, 361.21 \mathrm{~g} / \mathrm{mol}, 1.19 \mathrm{~g}$, yield $69 \%$, m.p. $279-281{ }^{\circ} \mathrm{C}$.

${ }^{1} \mathrm{HNMR}\left(400 \mathrm{MHz}, \mathrm{CDCl}_{3}, \delta\right): 9.56(\mathrm{~d}, 1 \mathrm{H}), 8.22-8.19(\mathrm{~d}, 2 \mathrm{H}), 8.04-8.02(\mathrm{~d}, 2 \mathrm{H})$, 7.76-7.72 (m, 2H), 7.51-7.47 (m, 2H)

${ }^{13} \mathrm{C}$ NMR $\left(100 \mathrm{MHz}_{\mathrm{CDCl}}, \delta\right): 180.3,135.9,135.8,131.0,130.5,129.9,129.5,129.5$, $123.9,123.6$

Dipirydo[3,2-a:2', $\left.3^{\prime}-c\right]$ phenazine-FN12

2,3-diaminobenzene $(1.0 \mathrm{~g}, 9.2 \mathrm{mmol})$ was refluxed with 1,10-phenanthroline-5,6-dione $(2 \mathrm{~g}, 9.2 \mathrm{mmol})$ in glacial acetic acid $(150 \mathrm{~mL})$ for $2 \mathrm{~h}$. The compound was obtained as yellow crystals: $\mathrm{C}_{18} \mathrm{H}_{10} \mathrm{~N}_{4}, 282.30 \mathrm{~g} / \mathrm{mol}, 1.74 \mathrm{~g}$, yield $65 \%$, m.p. $248-250{ }^{\circ} \mathrm{C}$, lit. 254-255 ${ }^{\circ} \mathrm{C}$ [61], 248-250 ${ }^{\circ} \mathrm{C}[57]$.

${ }^{1} \mathrm{HNMR}\left(400 \mathrm{MHz}, \mathrm{CDCl}_{3}, \delta\right): 9.71(\mathrm{~d}, 2 \mathrm{H}), 9.33-9.32(\mathrm{~d}, 2 \mathrm{H}), 8.40-8.38(\mathrm{~m}, 2 \mathrm{H})$, 7.97-7.95 (m, 2H), 7.86-7.83 (m, 2H)

${ }^{13} \mathrm{C} \mathrm{NMR}\left(100 \mathrm{MHz} \mathrm{CDCl}_{3}, \delta\right): 175.7,152.4,148.2,142.5,141.1,133.9,130.7,129.5$, 127.6, 124.2

Phenanthro[9, 10-g]pteridine-FN13

4,5-diaminopyrimidine $(1.0 \mathrm{~g}, 9.1 \mathrm{mmol})$ was refluxed with 9,10-phenanthrenequinone $(1.9 \mathrm{~g}, 9.1 \mathrm{mmol})$ in glacial acetic acid $(150 \mathrm{~mL})$ for $2 \mathrm{~h}$. The compound was obtained as yellow crystals: $\mathrm{C}_{18} \mathrm{H}_{10} \mathrm{~N}_{4}, 282.30 \mathrm{~g} / \mathrm{mol}, 0.96 \mathrm{~g}$, yield $71 \%$, m.p. 320-321 ${ }^{\circ} \mathrm{C}$.

${ }^{1} \mathrm{HNMR}\left(400 \mathrm{MHz}, \mathrm{DMSO}-\mathrm{d}_{6}, \delta\right): 9.55-9.52(\mathrm{~d}, 2 \mathrm{H}), 9.22-9.21(\mathrm{~d}, 2 \mathrm{H}), 8.41-8.37(\mathrm{~d}$, $2 \mathrm{H}), 8.08-8.04(\mathrm{~d}, 2 \mathrm{H}), 7.96-7.93(\mathrm{~d}, 2 \mathrm{H})$

${ }^{13} \mathrm{C}$ NMR $\left(100 \mathrm{MHz}, \mathrm{DMSO}-d_{6}, \delta\right): 172.4,152.8,148.3,142.2,141.3,133.5,131.7,129.6$, $127.4,125.0$

\subsection{Methods}

The ${ }^{1} \mathrm{H}$ NMR $(400 \mathrm{MHz})$ spectra were recorded on Bruker Ascend ${ }^{\mathrm{TM}} 400 \mathrm{NMR}$ spectrometers, Billerica, MA, United States. Deuterated chloroform $\left(\mathrm{CDCl}_{3}\right)$ and dimethylsulfoxide (DMSO-d6) was used as the solvent. Chemical shifts are reported in ppm relative to internal tetramethylsilane (TMS) reference, and coupling constants are reported in Hertz. Splitting patterns are described as singlet (s), doublet (d), triplet (t), quartet (q), or multiplet (m).

The melting points (uncorrected) were determined with the use of a Boëthius apparatus, Vernon Hills, IL, United States.

For thin layer chromatography, Merck Co, Kenilworth, NJ, United States., silica gel 60 F254 sheets ( $0.2 \mathrm{~mm}$ thickness) and chloroform as an eluent were used.

The electronic absorption $\left(\mathrm{c} \approx 10^{-4}-10^{-3} \mathrm{M}\right)$ and fluorescence spectra in ethyl acetate (EtOAc) were recorded at room temperature using Shimadzu UV-1280, Kioto, Japan and Hitachi F-7100 spectrophotometers, Tokio, Japan, respectively. The fluorescence quantum yield (FQY) was determined by a comparative method [62] using Coumarin 1 in ethanol $\left(\varphi_{\text {ref }}=0.64\right.$ [63] $)$ as the reference. The absorbances of both the dye and reference solution at an excitation wavelength (366 nm or $404 \mathrm{~nm}$ ) was ca. 0.1 .

The nanosecond laser flash photolysis experiments were performed using LKS.60 Laser Flash Photolysis apparatus (Applied Photophisics, Leatherhead, United Kingdom). Laser irradiation at $355 \mathrm{~nm}$ from the third harmonic of the Q-switched Nd:YAG laser from a Lambda Phisik/model LPY 150 operating at $65 \mathrm{~mJ} /$ pulse (pulse width about 4-5 ns) was 
used for the excitation. Transient absorbances at preselected wavelengths were monitored by a detection system consisting of a monochromator, a photomultiplier tube (Hamamatsu R955), and a pulsed xenon lamp (150 W) as a monitoring source. The signal from the photomultiplier was processed by a Hewlett-Packard/Agilent an Agilent Infiniium 54810A digital storage oscilloscope and an Acorn-compatible computer.

The quantum yield of the triplet state formation of the synthesized dyes was determined by two methods. The first one was described by Lament et al. [64] and was based on the analysis of transient absorption spectra, whereas the second one was described by Silverman and Foote [32]. The latter method was based on the analysis of ${ }^{1} \mathrm{H}$ NMR spectra recorded during the singlet oxygen oxidation of 2,3-diphenyl-p-dioxene (Scheme 1). The photooxidation reaction was carried out in a solution containing $0.6 \mathrm{~mL}$ of deuterated chloroform in which both $10 \mathrm{mg}$ of 2,3-diphenyl-p-dioxene and $5 \mathrm{mg}$ of the dye were dissolved. The solution was irradiated with LED F (dental-lamp-emitted) radiation in the range: $390-480 \mathrm{~nm}$. The radiation intensity was $18 \mathrm{~mW} / \mathrm{cm}^{2}$. During irradiation, the solution was stirred with a stream of oxygen. The formation of the photooxidation product was monitored by recording the ${ }^{1} \mathrm{H}$ NMR spectra.<smiles>CCC1COC(OOC2(c3ccc(C(=O)OCCOC(=O)c4ccccc4)cc3)Oc3ccccc3O2)(c2ccccc2)OC1</smiles>

Scheme 1. Oxidation of 2,3-diphenyl-p-dioxene with singlet oxygen.

The quantum yield of singlet oxygen production was calculated based on the rate of the ethylene glycol dibenzoate formation by the tested sensitizers compared to the rate of this product's formation in the presence of camphorquinone, which was used as a standard. The quantum yield of singlet oxygen generation by camphorquinone was $1.0[65,66]$. With a large excess of oxygen, the quantum yield of singlet oxygen formation was equal to the quantum yield of the triplet state formation [24].

$$
\Phi_{\mathrm{O}_{2}}=\Phi_{T}
$$

The effectiveness of the synthesized dyes as radical polymerization photosensitizers was tested by the microcalorimetric method $[67,68]$. The measurements were performed in a homemade microcalorimeter using a semiconducting diode immersed in a 2-3 mm thick layer $(0.25 \mathrm{~mL})$ of a cured sample as a temperature sensor. The initial rate of polymerization was determined by the measurements of the rate of the heat evolution during polymerization for the initial time. A diode-pumped solid-state laser $(408 \mathrm{~nm})$ with an intensity of $18 \mathrm{~mW} / \mathrm{cm}^{2}$ (Mean Well model NES-15-12) was used as the light source. The light intensity was measured by a Coherent model Fieldmaster power meter. The distance of the sample from the light source was the same for all measurements. Each measurement was repeated at least three times.

The photopolymerization compositions were composed of $0.9 \mathrm{~g}$ of trimethylolpropane triacrylate (TMPTA) and $0.1 \mathrm{~mL}$ of 1-methyl-2-pyrrolidinone (MP) containing appropriate amounts of the photosensitizer (synthesized phenazine based dyes) and the co-initiator [(3,4-dimethoxyphenyl)sulfanyl]acetic acid (MKTFO). The concentration of the dyes was $2 \times 10^{-3}-5.63 \times 10^{-4} \mathrm{M}$ (depending on the molar absorption coefficient at an excitation wavelength), whereas the concentration of the co-initiator was $0.1 \mathrm{M}$. As a reference sample, a polymerizing mixture without a co-initiator was used.

In order to compare the quantum efficiency of triplet state formation and the photoinitiating efficiency of the TMPTA, radical polymerization by the synthesized compounds 
with a commercial compound, the camphorquinone $\left(\lambda_{\max }=472 \mathrm{~nm}, \varepsilon=40 \mathrm{M}^{-1} \mathrm{~cm}^{-1}\right.$ in ethyl acetate), was used. Its concentration in the polymerization experiments was $0.675 \mathrm{M}$.

\section{Results}

The analysis of the electronic absorption spectra of the synthesized compounds indicated that the spectra were typical for heterocyclic aromatic compounds with condensed rings and that they were characterized by several absorption maxima in the longwavelength region (Figure 1). They displayed main absorption bands in the range from $350 \mathrm{~nm}$ to $530 \mathrm{~nm}$. Thus, the compounds afforded deeply colored solutions with molar extinction coefficients ranging from $0.96 \times 10^{4} \mathrm{M}^{-1} \mathrm{~cm}^{-1}$ to $2.56 \times 10^{4} \mathrm{M}^{-1} \mathrm{~cm}^{-1}$ for the most intense band, which is typical for $\pi \rightarrow \pi^{*}$ transitions. The basic spectral data are collected in Table 1.

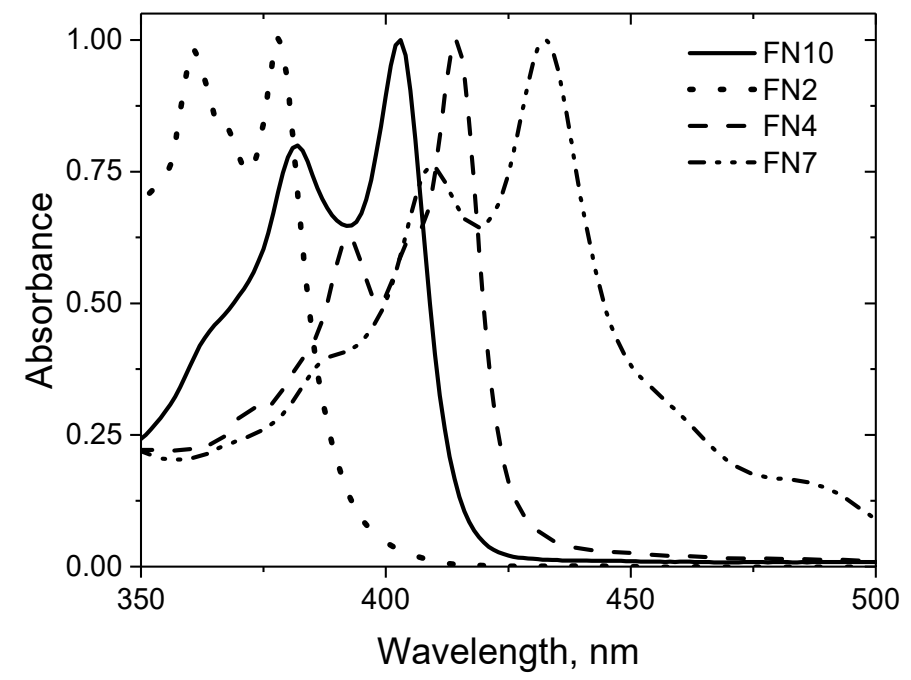

Figure 1. Fragments of the electronic absorption spectra of the selected dyes in ethyl acetate.

The position of the absorption bands was clearly influenced by the dye structure, i.e., the number of conjugated double bonds, the arrangement of aromatic rings, and the number and location of nitrogen atoms. The increase in the number of conjugated double bonds in the molecule (FN1, FN2, and FN3; FN6 and FN7) and the angular arrangement of the rings (FN4 versus FN3) caused a bathochromic effect. The red shift of the absorption maximum was also observed with an increase in the number of nitrogen atoms in the molecule (FN9, FN10, FN11) as well as the presence of a heavy atom (FN2 and FN9) (Figure $\mathrm{S} 1$ in ESI).

In general, the compounds had high molar absorption coefficients and appropriate spectral characteristics enabling selective excitation of the sensitizer. It follows that the dyes met the requirements for singlet oxygen sensitizers.

Figure 2 shows the fluorescence spectra for selected dyes.

As for absorption spectra, the position of the fluorescence maximum depended on the dye structure. The number of both conjugated double bonds and nitrogen atoms in the molecule, the angular arrangement of the rings, and the presence of a heavy atom affected the fluorescence band position and its intensity (Figure S2 in ESI). The data in Table 1 show that the fluorescence quantum yield varied from 0.025 (FN6 and FN7) for compounds with a high singlet-oxygen-generating ability to 0.11 (FN1) for the compound showing a very low singlet oxygen quantum yield (Table 2). 


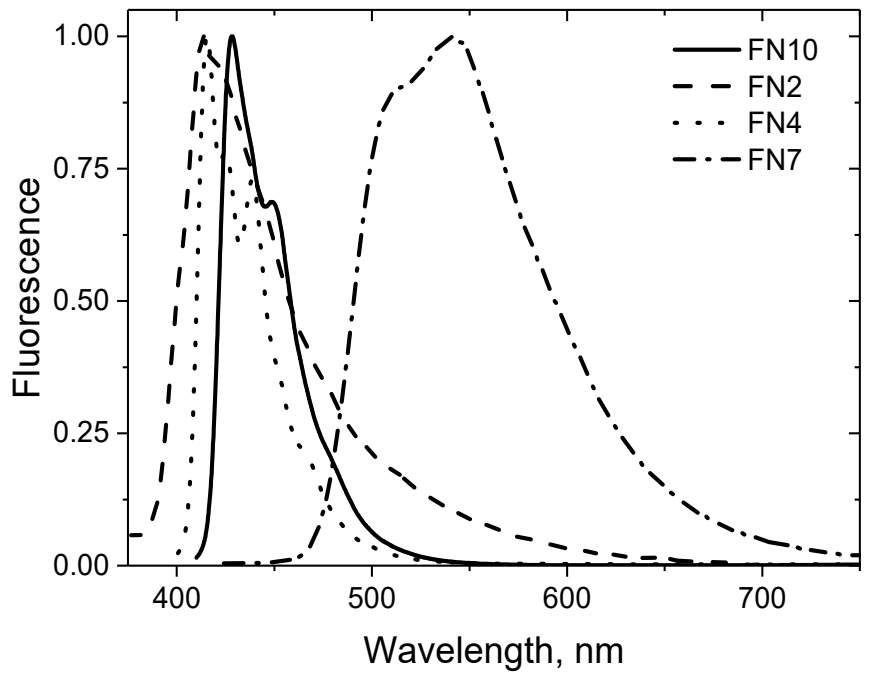

Figure 2. Fluorescence spectra of the selected dyes in ethyl acetate.

Table 2. Quantum yield of the singlet oxygen formation $\left(\Phi_{1} \mathrm{O}_{2}\right)$, quantum yield of the triplet state $\left(\Phi_{\mathrm{T}}\right)$, and initial rate of photoinitiated polymerization $\left(R_{p}\right)$ for the dyes tested.

\begin{tabular}{cccc}
\hline Dye & $\boldsymbol{R}_{\boldsymbol{p}} \boldsymbol{\mu} \boldsymbol{\mu m o l \mathbf { ~ s } ^ { - 1 }}$ & $\boldsymbol{\Phi}_{\mathbf{1}_{\mathbf{2}}}$ & $\boldsymbol{\Phi}_{\boldsymbol{T}}$ \\
\hline FN1 & 44.1 & 0.06 & - \\
FN2 & 112.0 & 0.32 & 0.30 \\
FN3 & 107.7 & 0.36 & 0.37 \\
FN4 & 180.2 & 0.77 & 0.75 \\
FN5 & 101.7 & 0.32 & - \\
FN6 & 196.3 & 0.92 & 0.90 \\
FN7 & 183.9 & 0.80 & 0.79 \\
FN8 & 107.6 & 0.32 & 0.30 \\
FN9 & 147.9 & 0.67 & - \\
FN10 & 136.7 & 0.51 & - \\
FN11 & 115.9 & 0.31 & - \\
FN12 & 103.3 & 0.30 & - \\
FN13 & 54.4 & 0.09 & - \\
CQ & 234.2 & 1.00 & - \\
\hline
\end{tabular}

The quantum yield of the triplet state formation was determined by the comparative method using camphorquinone as a standard. The method was based on the oxidation of 2,3-diphenyl- $p$-dioxene by singlet oxygen produced in a photochemical process involving the excitation of triplet oxygen with UV-vis light in the presence of a sensitizing dye. The formation of the photooxidation product was monitored by the analysis of the ${ }^{1} \mathrm{H} N \mathrm{NR}$ spectra recorded for the initial solution and after different times of irradiation (Figures 3 and 4). 


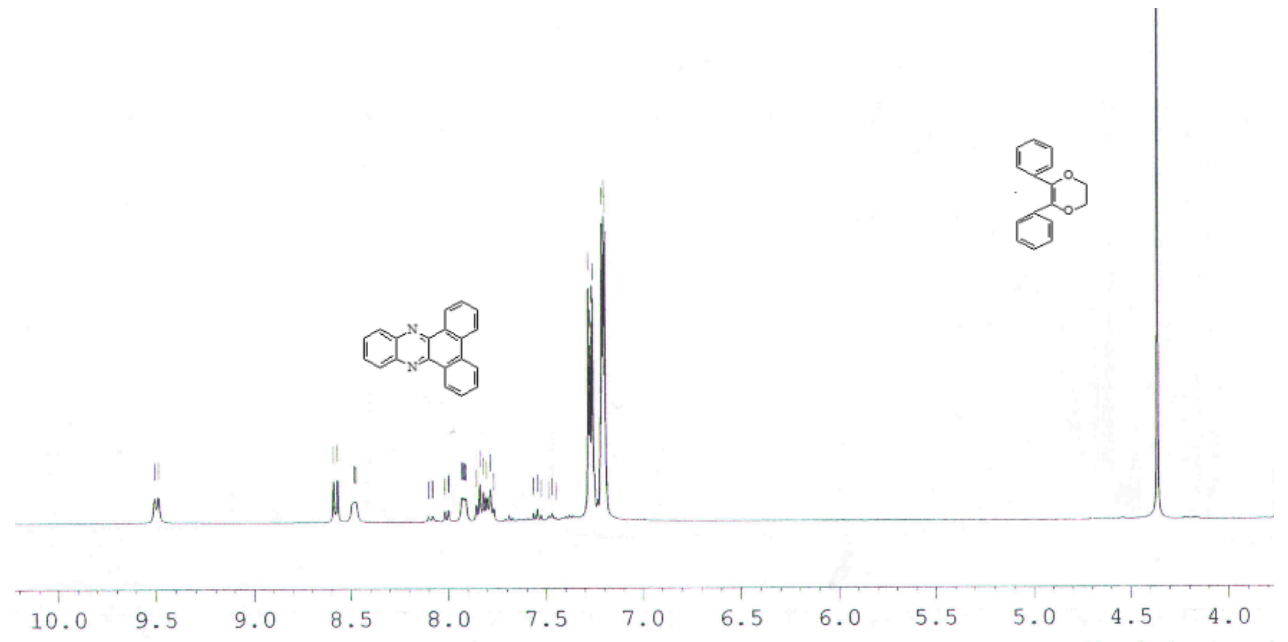

Figure 3. ${ }^{1} \mathrm{H}$ NMR spectrum of a mixture of dibenzo[a.c]phenazine sensitizer and 2,3-diphenyl- $p$ dioxene in $\mathrm{CDCl}_{3}$ before irradiation.

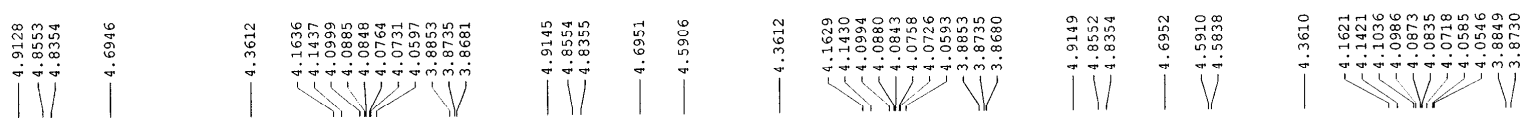

A

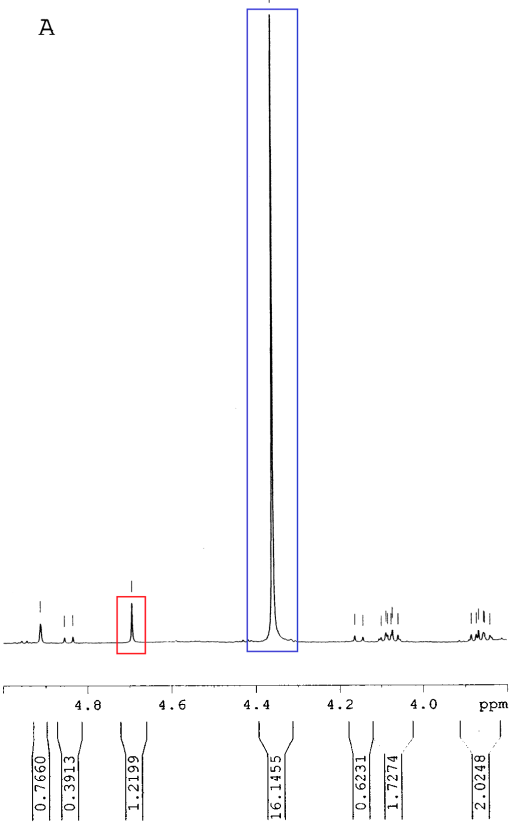

B

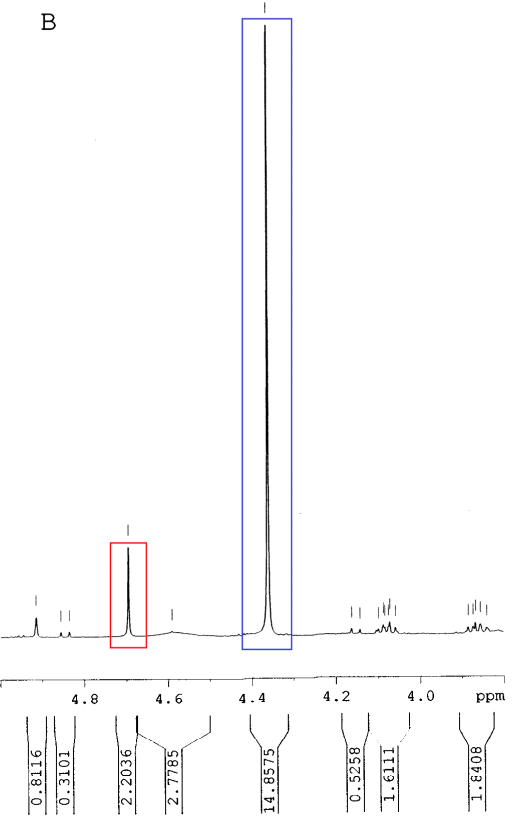

$\mathrm{C}$

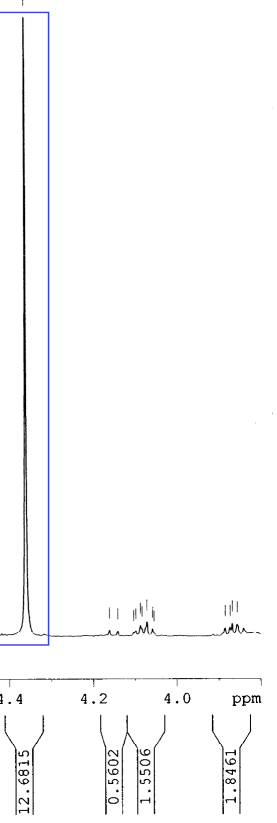

Figure 4. ${ }^{1} \mathrm{H}$ NMR spectra of a mixture of dibenzo[a.c]phenazine (sensitizer) and 2,3-diphenyl- $p$-dioxene in $\mathrm{CDCl}_{3}$; irradiation time: A-10 $\mathrm{min}, \mathrm{B}-20 \mathrm{~min}$, and C-30 min.

The ${ }^{1} \mathrm{H}$ NMR spectra of the tested compounds in the presence of 2,3-diphenyl- $p$ dioxene in $\mathrm{CDCl}_{3}$, recorded after different irradiation times, showed the formation of photooxidation products according to Equation (5) (Figure 3 and Figure S3 in ESI). Their analysis allowed us to distinguish the substrate from the oxidation product, for which the relevant values of characteristic chemical proton shifts are presented in Table 3. 
Table 3. Characteristic values of chemical shifts for individual compounds and areas under the peaks after the specified irradiation time assigned from ${ }^{1} \mathrm{H}$ NMR spectra.

\begin{tabular}{|c|c|c|c|c|}
\hline \multirow{2}{*}{ Compound } & \multirow{2}{*}{$\sigma, \mathrm{ppm}$} & \multicolumn{3}{|c|}{ Area } \\
\hline & & $10 \mathrm{~min}$ & $20 \mathrm{~min}$ & $30 \mathrm{~min}$ \\
\hline 2,3-diphenyl-p-dioxene & $4.3612(\mathrm{~s}, 4 \mathrm{H})$ & 16.1453 & 14.8573 & 12.6815 \\
\hline ethylene glycol dibenzoate & $4.5916(\mathrm{~s}, 4 \mathrm{H})$ & 1.2199 & 2.2026 & 3.4956 \\
\hline
\end{tabular}

The analysis of ${ }^{1} \mathrm{H}$ NMR spectra of the tested compounds in a mixture with 2,3diphenyl- $p$-dioxene in $\mathrm{CDCl}_{3}$ indicated a well-separated singlet for two methylene groups from the 2,3-diphenyl-p-dioxene. After gradual irradiation, the proton spectrum of the same solution showed considerable changes in chemical shifts. It became evident that the signal intensity at $4.3612 \mathrm{ppm}$ decreased gradually accompanied by the appearance of a new signal at $4.5916 \mathrm{ppm}$. The intensity of the new singlet increased proportionally with the irradiation time. The location of the signal was in perfect agreement with the two methylene groups in ethylene glycol dibenzoate, which was formed during photooxidation of the 2,3-diphenyl-p-dioxene sensitized by the tested compounds. The quantum yield of singlet oxygen production in the presence of the tested sensitizers is collected in Table 3. These values can be considered equal to the quantum yield of the triplet state formation when determined under the conditions of excess oxygen.

The quantum yield of the triplet state formation for selected sensitizers was also determined from the analysis of transient absorption spectra obtained using the nanosecond laser flash photolysis technique. An exemplary spectrum of FN2 in deoxygenated acetonitrile solution is shown in Figure 5. A readily detectable transient absorption spectra peaking at $390 \mathrm{~nm}, 470 \mathrm{~nm}$, and $620 \mathrm{~nm}$ decay in a few milliseconds according to first-order kinetics. They were not observed in an oxygen-saturated solution.

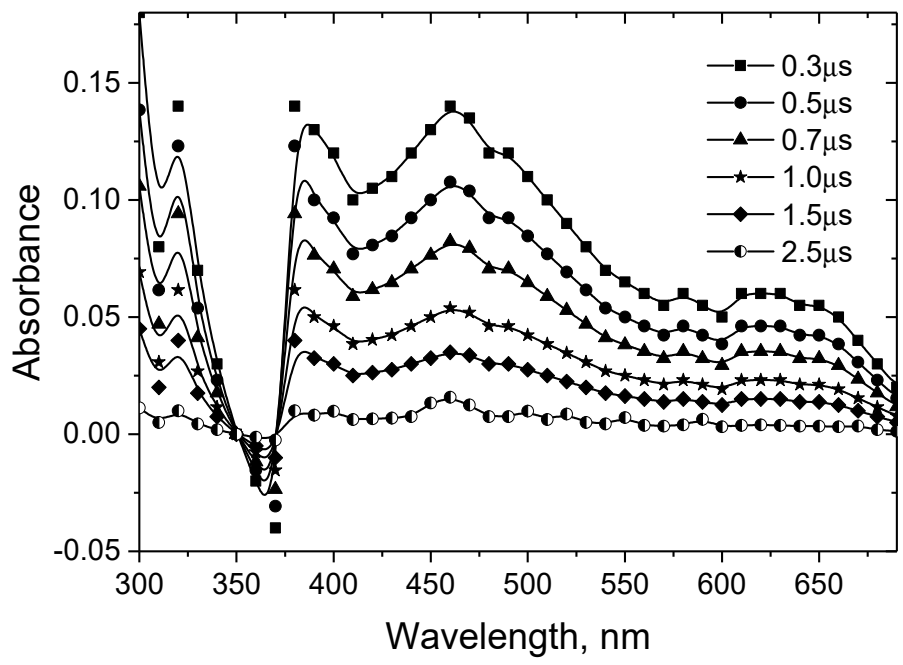

Figure 5. Laser flash photolysis spectra of the dye FN2 in acetonitrile recorded after irradiation with laser pulses of $355 \mathrm{~nm}$. Delay times shown in legends.

The quantum yields of the triplet state formation of the tested sensitizers were determined from the triplet formation curves using methodology given by Lament et al. [64] and by us [36]. The method is based on quantitative analysis of the ground state recovery and its deconvolution, which concerns an instrumental response function. A typical example of such approach is shown in Figure 5, and obtained data are summarized in Table 2. According to Equation (6), the yield of triplet formation $\left(\Phi_{\mathrm{T}}\right)$ is proportional to the ratio of the initial increment in absorbance immediately after the flash $\left(\Delta \mathrm{A}_{t}\right)$ and the value at 
the maximum ground state depletion (the former is compared to the long delay, "plateau" region) (cf. Figure 6):

$$
\Phi_{T}=\frac{\Delta A_{t}}{\Delta \mathrm{A}_{\max }}
$$

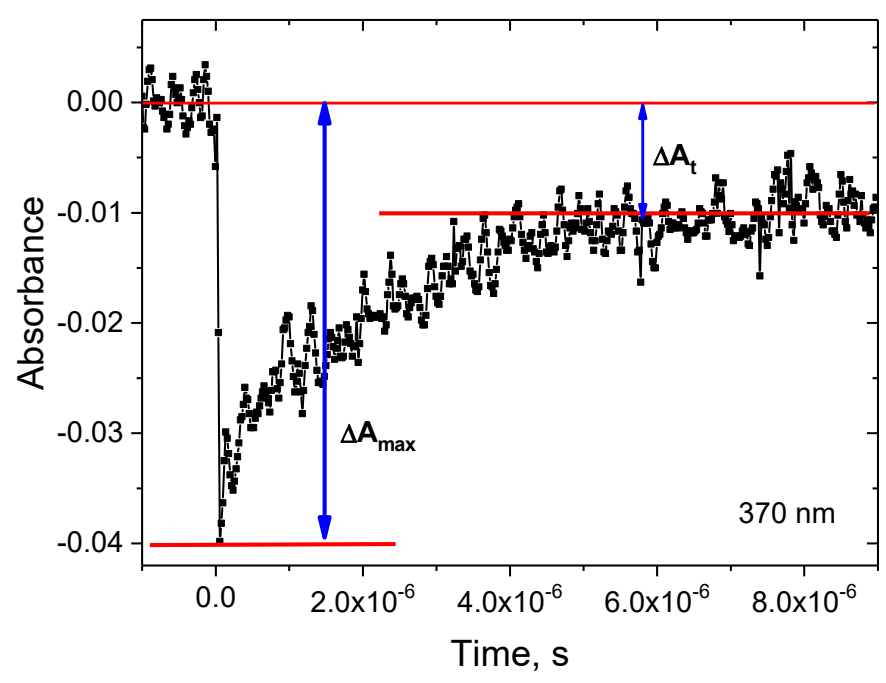

Figure 6. Analysis of $\Delta \mathrm{A}(\mathrm{t})$ curve recorded for FN2 in acetonitrile at $370 \mathrm{~nm}$.

The comparison of the data collected in Table 2 and illustrated in Figure 7 shows unequivocally the equivalence of the methods for assessing the quantum yield of the triplet state formation and the validity of Equation (5).

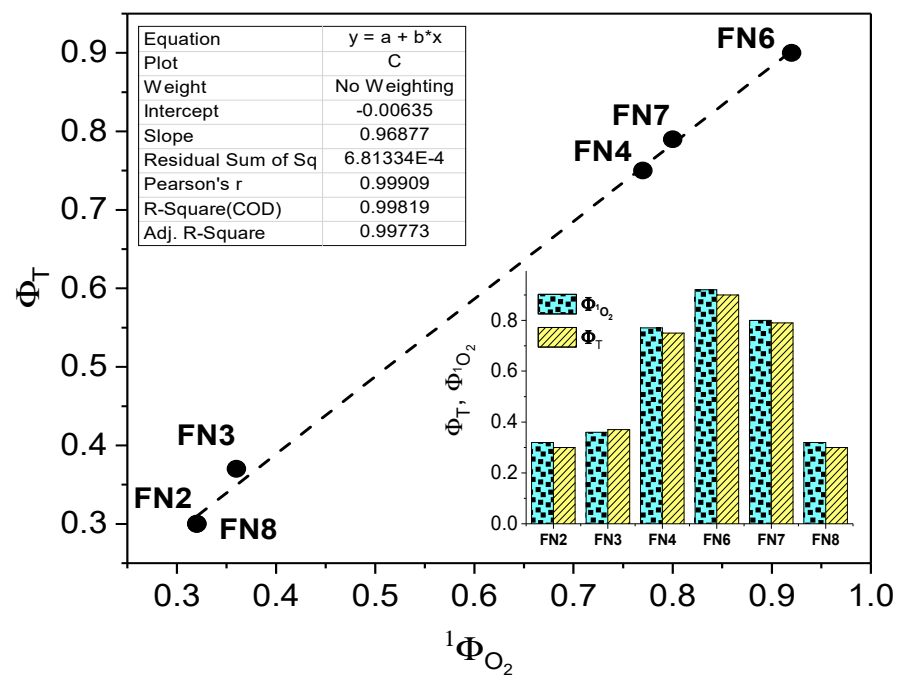

Figure 7. Comparison of the quantum yield of singlet oxygen generation to the quantum yield of triplet state formation for selected sensitizers.

From the viewpoint of the photochemical properties of the tested compounds, the data presented in Table 2 indicate that the structure of the sensitizer tested had a significant influence on the ability to generate singlet oxygen and, thus, to form a triplet state.

Introduction of a bromide atom to the phenazine scaffold (dye FN2 vs. FN9) increased the ability to generate singlet oxygen in the photochemical process. Furthermore, the quantum yields of triplet state formation decreased from about 0.67 to 0.51 and to 0.31 for dyes containing two (FN9), three (FN10), and four (FN11) nitrogen atoms, respectively. This proves that the modification of the phenazine structure by introducing more nitrogen 
atoms into the molecule leads to a reduction in the ability of the compounds to sensitize singlet oxygen. The ability to generate singlet oxygen by the phenazine derivatives was also influenced by the number of conjugated double bonds and the arrangement of aromatic rings (linear and/or angular system). The highest quantum yield of singlet oxygen production was characterized by phenazine derivatives with angular arrangements of the aromatic rings (FN4 compared to FN3 and FN6 compared to FN 7).

Since the quantum yield of singlet oxygen generation at a high excess of oxygen translates into the quantum yield of the triplet state formation (which is a desired feature of photoinitiators), the obtained sensitizers were used to initiate the TMPTA polymerization. According to Equation (7) $[67,68]$, the rate of photoinitiated radical polymerization is directly proportional to the square root of the quantum yield of triplet state formation:

$$
R_{p}=-\frac{d[M]}{\mathrm{dt}}=k_{p}[M] \sqrt{\frac{I_{a} \Phi_{T}}{k_{t}}}
$$

where:

$M$-the molar concentration of the monomer;

$k_{p}$-the polymerization rate constant;

$I_{a}$-the absorbed radiation intensity;

$\varphi_{T}$-the quantum yield of triplet state formation;

$k_{t}$-the macroradical termination rate constant;

The efficiency of the polymerization initiated by phenazine dye-[(3,4-dimethoxyphenyl)sulfanyl]acetic acid (MKTFO) systems was assessed from the heat flow during the visible light irradiation. Typical kinetic curves obtained for the photoinitiated polymerization of the TMPTA-MP (9:1) mixture recorded for selected dyes are shown in Figures 8 and 9 for illustration. The rates of photoinitiated polymerization determined for all the tested photoredox pairs are collected in Table 2.

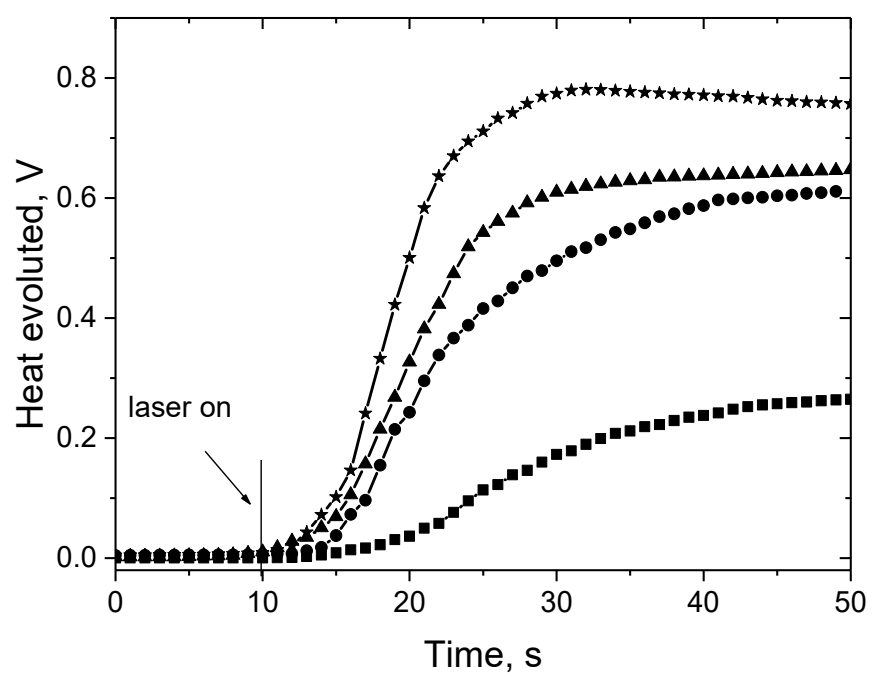

Figure 8. Family of kinetic curves recorded during the measurements of the heat flow emitted during the photoinitiated polymerization of the TMPTA-MP mixture initiated by tested dyes- $[(3,4-$ dimethoxyphenyl)sulfanyl]acetic acid couples. The co-initiator concentration was $0.1 \mathrm{M}$, and the light intensity of the diode laser $(408 \mathrm{~nm})$ was $18 \mathrm{~mW} / \mathrm{cm}^{2}$. The applied dyes possessed various

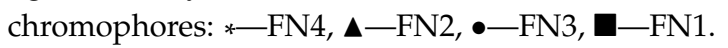




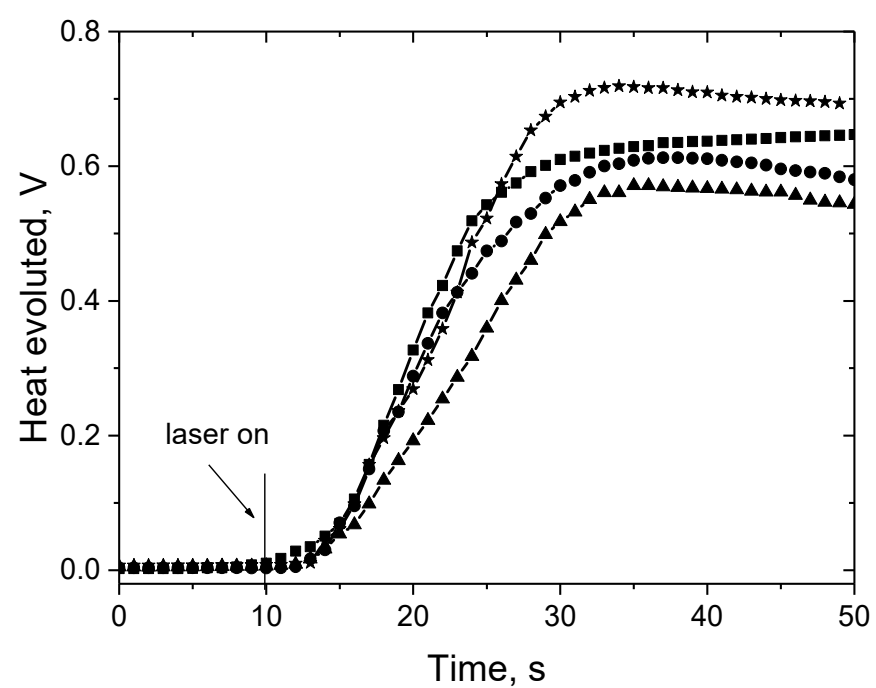

Figure 9. Family of kinetic curves recorded during the measurements of the heat flow emitted during the photoinitiated polymerization of the TMPTA-MP mixture initiated by tested dyes- $[(3,4-$ dimethoxyphenyl)sulfanyl]acetic acid couples. The co-initiator concentration was $0.1 \mathrm{M}$, and the light intensity of the diode laser $(408 \mathrm{~nm})$ was $18 \mathrm{~mW} / \mathrm{cm}^{2}$. The applied dyes possessed various chromophores: $\mathbf{\square}-\mathrm{FN} 2, *-\mathrm{FN} 12, \bullet-\mathrm{FN} 8, \boldsymbol{\Delta}-\mathrm{FN} 13$.

The analysis of the presented curves and the $R_{p}$ values collected in Table 2 indicated that the highest efficiency of photoinitiating polymerization was characterized by those phenazine derivatives for which the quantum yields of singlet oxygen generation (formation of a triplet state) were the highest.

The effectiveness of the synthesized dyes in the radical polymerization photoinitiation, characterized by the initial rate $R_{p}$, was compared to the camphorquinone-a commercial photoinitiator used in dentistry (Figure 10).

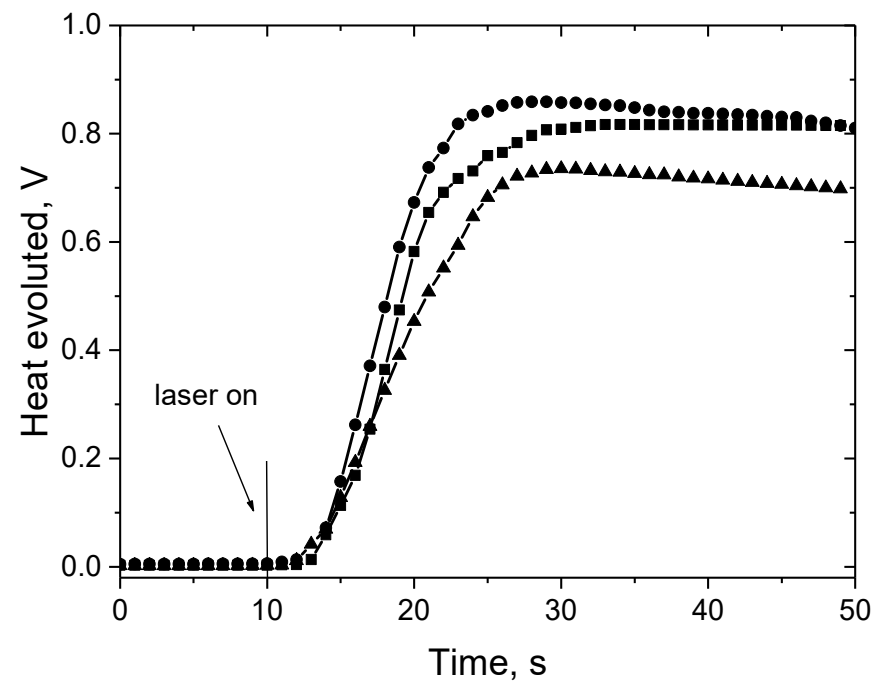

Figure 10. Family of kinetic curves recorded during polymerization of TMPTA-MP photoinitiated with $\bullet-C Q, \mathbf{\square}-\mathrm{FN7}, \mathbf{\Delta}-\mathrm{FN} 9$ in the presence of the MKTFO co-initiator $(0.1 \mathrm{M})$; the light intensity of diode laser $(408 \mathrm{~nm})$ was $18 \mathrm{~mW} / \mathrm{cm}^{2}$.

The results clearly indicated that the initial rate of radical polymerization photoinitiated by phenazine derivatives was comparable to the polymerization rate in which commercial CQ was used as a photoinitiator (Figure 10). However, the concentration of the synthesized dyes in the polymerizing composition was about 2000 times lower than the 
CQ. The CQ molar absorption coefficient at the excitation wavelength $\left(\lambda_{\max }=408 \mathrm{~nm}\right)$ was only $\varepsilon=8 \mathrm{M}^{-1} \mathrm{~cm}^{-1}$, whereas for the synthesized dyes, e.g., FN9 $\left(\lambda_{\max }=408 \mathrm{~nm}\right)$, it was $\varepsilon=15,400 \mathrm{M}^{-1} \mathrm{~cm}^{-1}$. This made it possible to obtain thick polymer layers $(4 \mathrm{~mm})$ that did not contain significant amounts (about $0.675 \mathrm{M}$ ) of unreacted CQ and co-products formed during the photochemical reaction (the radical resulting from the dye usually does not initiate a chain reaction but participates in side reactions).

According to Equation (7), the radicals' formation takes place in the triplet excited state of the dye. If this assumption is correct for the tested photoinitiator systems, the initial rate $\left(R_{p}\right)$ of TMPTA photoinitiated polymerization should depend linearly on the square root of the quantum yield of the triplet state. On the basis of the correlation shown in Figure 11, it can be concluded that the electron transfer process from the electron donor (MKTFO) to the photosensitizers (FN1-FN13) occured in the triplet excited state.

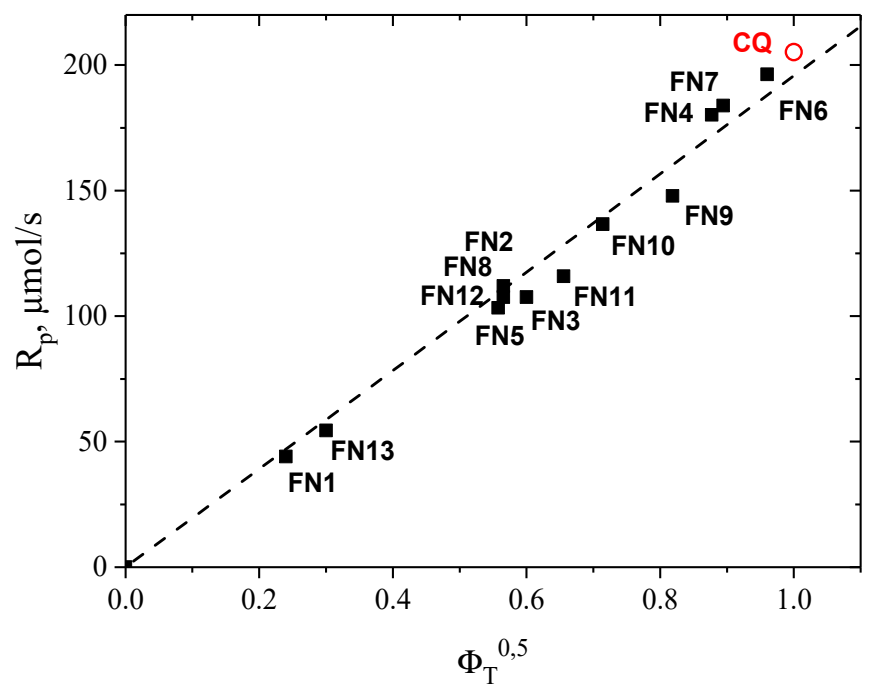

Figure 11. Correlation between the rate of photoinitiated polymerization of TMPTA and the square root of the quantum yield of the triplet state formation for FN1-FN13 and $\bigcirc-C Q$ in the presence of MKTFO co-initiator $(0.1 \mathrm{M})$; the light intensity of diode laser $(408 \mathrm{~nm})$ was $18 \mathrm{~mW} / \mathrm{cm}^{2}$.

\section{Conclusions}

The obtained results show that phenazine derivatives are interesting and efficient singlet oxygen sensitizers. In some cases, the quantum yield of generating singlet oxygen was close to 1.0. Increasing the number of nitrogen atoms in the modified phenazine structures clearly decreased the quantum yield of the triplet state formation. This proves that the modified phenazine structures containing large number of nitrogen atoms are weak singlet oxygen sensitizers. In addition, the ability to generate singlet oxygen by the modified phenazine structures was also influenced by the number of conjugated double bonds and the arrangement of aromatic rings. Angular arrangement of aromatic rings in the structure of phenazine derivatives guarantees obtaining good singlet oxygen sensitizers.

In conditions of high oxygen excess, the quantum yield of singlet oxygen generation translates into the quantum yield of the triplet state formation, which allows the obtained photosensitizers to be used in the TMPTA radical polymerization process. The initiation efficiency of TMPTA polymerization increases with the increase in the quantum yield of the singlet oxygen production and, thus, the quantum yield of the triplet state formation.

The greatest application potential reveals compounds having a heavy atom or an angular arrangement of the rings. The analysis of the data described in this study and in our previous articles [69-71] leads to the conclusion that the appropriate modification of the dye structure allowed the obtainment of compounds that are not only effective photosensitizers in systems initiating radical polymerization but also sensitizers of singlet oxygen. 
Supplementary Materials: The following are available online at https:/ / www.mdpi.com/article/10 $.3390 / \mathrm{ma14113085/s1}$, Figure S1. Normalized electronic absorption spectra of phenazine derivatives in ethyl acetate. Figure S2. Normalized fluorescence spectra of phenazine derivatives in ethyl acetate illustrating the influence of dye structure on the bands position; Ex $=366 \mathrm{~nm}$ or $404 \mathrm{~nm}$. Figure S3. ${ }^{1} \mathrm{H}$ NMR spectra of a mixture of dibenzo[a.c]phenazine FN2 (sensitizer) and 2,3-diphenyl-p-dioxene in $\mathrm{CDCl}_{3}$ after different irradiation time; dental lamp, $18 \mathrm{~mW}$.

Author Contributions: Conceptualization I.P. and Z.K.; synthesized the compounds, performed all experiments, analyzed the obtained data, prepared the Polish version of the article, created the figures, and collected data in tables, I.P.; wrote the English version of the article, corrected some figures and collected data, discussed the results and conclusions, B.J. All authors have read and agreed to the published version of the manuscript.

Funding: The financial support of the Ministry of Science and Higher Education Republic of Poland (BN 7/2019) is gratefully acknowledged.

Data Availability Statement: The data is provided by Ilona Pyszka (UTP University of Science and Technology), please contact Ilona.Pyszka@utp.edu.pl. The data is not publicly available apart from the data contained in the article or Supplementary Materials.

Conflicts of Interest: The authors declare no conflict of interest.

\section{References}

1. Hayyan, M.; Hashim, M.A.; Alnashef, I.M. Superoxide Ion: Generation and Chemical Implications. Chem. Rev. 2016, 116, 3029-3085. [CrossRef] [PubMed]

2. Wilkinson, F.; Helman, W.P.; Ross, A.B. Quantum Yields for the Photosensitized Formation of the Lowest Electronically Excited Singlet State of Molecular Oxygen in Solution. J. Phys. Chem. Ref. Data 1993, 22, 113-262. [CrossRef]

3. Olea, A.; Wilkinson, F. Singlet Oxygen Production from Excited Singlet and Triplet States of Anthracene Derivatives in Acetonitrile. J. Phys. Chem. 1995, 99, 4518-4524. [CrossRef]

4. Wilkinson, F.; Helman, W.P.; Ross, A.B. Rate Constants for the Decay and Reactions of the Lowest Electronically Excited Singlet State of Molecular Oxygen in Solution. An Expanded and Revised Compilation. J. Phys. Chem. Ref. Data 1995, $24,663-677$. [CrossRef]

5. Khan, A.U.; Kasha, M. Red Chemiluminescence of Molecular Oxygen in Aqueous Solution. J. Chem. Phys. 1963, $39,2105$. [CrossRef]

6. Seliger, H. A photoelectric method for the measurement of spectra of light sources of rapidly varying intensities. Anal. Biochem. 1960, 1, 60-65. [CrossRef]

7. Foote, C.S.; Wexler, S.; Ando, W.; Higgins, R. Chemistry of singlet oxygen. IV. Oxygenations with hypochlorite-hydrogen peroxide. J. Am. Chem. Soc. 1968, 90, 975-981. [CrossRef]

8. Wasserman, H.H.; Scheffer, J.R. Singlet oxygen reactions from photoperoxides. J. Am. Chem. Soc. 1967, 89, 3073-3075. [CrossRef]

9. Turro, N.J.; Chow, M.-F.; Blaustein, M.A. Generation, diffusivity, and reactivity of singlet oxygen in polymer matrices. A convenient and sensitive chemiluminescent technique. J. Am. Chem. Soc. 1978, 100, 7110-7112. [CrossRef]

10. Steer, R.; Darnall, K.; Pitts, J. The base-induced decomposition of peroxyacetylnitrate. Tetrahedron Lett. 1969, 10, 3765-3767. [CrossRef]

11. Murray, R.W.; Kaplan, M.L. Singlet oxygen sources in ozone chemistry. Chemical oxygenations using the adducts between phosphite esters and ozone. J. Am. Chem. Soc. 1969, 91, 5358-5364. [CrossRef]

12. Wasserman, E.; Murray, R.W.; Kaplan, M.L.; Yager, W.A. Electron paramagnetic resonance of 1.DELTA. oxygen from a phosphiteozone complex. J. Am. Chem. Soc. 1968, 90, 4160-4161. [CrossRef]

13. Corey, E.J.; Taylor, W.C. A Study of the Peroxidation of Organic Compounds by Externally Generated Singlet Oxygen Molecules. J. Am. Chem. Soc. 1964, 86, 3881-3882. [CrossRef]

14. Foner, S.N.; Hudson, R.L. Metastable Oxygen Molecules Produced by Electrical Discharges. J. Chem. Phys. 1956, $25,601$. [CrossRef]

15. Krieger-Liszkay, A. Singlet oxygen production in photosynthesis. J. Exp. Bot. 2004, 56, 337-346. [CrossRef] [PubMed]

16. Harrison, R.M. Pollution: Causes, Effects and Control; Royal Society of Chemistry: Cambridge, UK, 2001.

17. Wentworth, P.; McDunn, J.E.; Wentworth, A.D.; Takeuchi, C.; Nieva, J.; Jones, T.; Bautista, C.; Ruedi, J.M.; Gutierrez, A.; Janda, K.D.; et al. Evidence for Antibody-Catalyzed Ozone Formation in Bacterial Killing and Inflammation. Science 2002, 298, 2195-2199. [CrossRef]

18. Gollnick, K. Type II Photooxygenation Reactions in Solution. In Advances in Photochemistry; Wiley: Hoboken, NJ, USA, 2007; pp. 1-122.

19. Nowakowska, M. Solvent effect on the quantum yield of the self-sensitized photoperoxidation of 1,3-diphenylisobenzofuran. J. Chem. Soc. Faraday Trans. 1 Phys. Chem. Condens. Phases 1984, 80, 2119-2126. [CrossRef] 
20. Kawaoka, K.; Khan, A.U.; Kearns, D.R. Role of Singlet Excited States of Molecular Oxygen in the Quenching of Organic Triplet States. J. Chem. Phys. 1967, 46, 1842-1853. [CrossRef]

21. Gollnick, K.; Schenck, G.O. Mechanism and stereoselectivity of photosensitized oxygen transfer reactions. Pure Appl. Chem. 1964, 9,507-526. [CrossRef]

22. DeRosa, M.C. Photosensitized singlet oxygen and its applications. Coord. Chem. Rev. 2002, 233-234, 351-371. [CrossRef]

23. Atmaca, G.Y. Investigation of The Differences Between Sono-Photochemical and Photochemical Studies for Singlet Oxygen Generation of Indium Phthalocyanine. Inorg. Chim. Acta 2021, 515, 120052. [CrossRef]

24. Pączkowski, J. Monomeryczne i Polimeryczne Pochodne Różu Bengalskiego; ATR: Bydgoszcz, Poland, 1988.

25. Schweitzer, C.; Schmidt, R. Physical Mechanisms of Generation and Deactivation of Singlet Oxygen. Chem. Rev. 2003, 103, 1685-1758. [CrossRef]

26. Redmond, R.W.; Gamlin, J.N. A Compilation of Singlet Oxygen Yields from Biologically Relevant Molecules. Photochem. Photobiol. 1999, 70, 391-475. [CrossRef]

27. Juzeniene, A.; Peng, Q.; Moan, J. Milestones in the development of photodynamic therapy and fluorescence diagnosis. Photochem. Photobiol. Sci. 2007, 6, 1234-1245. [CrossRef] [PubMed]

28. He, Y.; Liu, S.H.; Yin, J.; Yoon, J. Sonodynamic and chemodynamic therapy based on organic/organometallic sensitizers. Coord. Chem. Rev. 2021, 429, 213610. [CrossRef]

29. Kumar, P.P.P.; Rahman, A.; Goswami, T.; Ghosh, H.N.; Neelakandan, P.P. Fine-Tuning Plasmon-Molecule Interactions in GoldBODIPY Nanocomposites: The Role of Chemical Structure and Noncovalent Interactions. ChemPlusChem 2021, 86, 87-94. [CrossRef]

30. Atmaca, G.Y. Investigation of singlet oxygen efficiency of di-axially substituted silicon phthalocyanine with sono-photochemical and photochemical studies. Polyhedron 2021, 193, 114894. [CrossRef]

31. Bartusik, D.; Aebisher, D.; Lyons, A.M.; Greer, A. Bacterial Inactivation by a Singlet Oxygen Bubbler: Identifying Factors Controlling the Toxicity of $1 \mathrm{O} 2$ Bubbles. Environ. Sci. Technol. 2012, 46, 12098-12104. [CrossRef]

32. Silverman, S.K.; Foote, C.S. Singlet oxygen and electron-transfer mechanisms in the dicyanoanthracene-sensitized photooxidation of 2,3-diphenyl-1,4-dioxene. J. Am. Chem. Soc. 1991, 113, 7672-7675. [CrossRef]

33. Fouassier, J.P.; Allonas, X. Dyes and Chromophores in Polymer Science; John Wiley \& Sons: Hoboken, NJ, USA, 2015.

34. Czech, Z.; Kabatc, J.; Bartkowiak, M.; Licbarski, A.; Mozelewska, K.; Kwiatkowska, D. Novel Photoreactive Pressure-Sensitive Adhesives (PSA) Based on Acrylics Containing Additionable Photoinitiators. Materials 2020, 13, 5151. [CrossRef]

35. Balcerak, A.; Kwiatkowska, D.; Iwińska, K.; Kabatc, J. Highly efficient UV-Vis light activated three-component photoinitiators composed of tris(trimethylsilyl)silane for polymerization of acrylates. Polym. Chem. 2020, 11, 5500-5511. [CrossRef]

36. Ścigalski, F.; Jędrzejewska, B. Structural effect of oxazolone derivatives on the initiating abilities of dye-borate photoredox systems in radical polymerization under visible light. RSC Adv. 2020, 10, 21487-21494. [CrossRef]

37. Jędrzejewska, B.; Wejnerowska, G. Highly Effective Sensitizers Based on Merocyanine Dyes for Visible Light Initiated Radical Polymerization. Polymers 2020, 12, 1242. [CrossRef]

38. Topa, M.; Hola, E.; Galek, M.; Petko, F.; Pilch, M.; Popielarz, R.; Morlet-Savary, F.; Graff, B.; Lalevée, J.; Ortyl, J. One-component cationic photoinitiators based on coumarin scaffold iodonium salts as highly sensitive photoacid generators for 3D printing IPN photopolymers under visible LED sources. Polym. Chem. 2020, 11, 5261-5278. [CrossRef]

39. Topa, M.; Ortyl, J. Moving Towards a Finer Way of Light-Cured Resin-Based Restorative Dental Materials: Recent Advances in Photoinitiating Systems Based on Iodonium Salts. Materials 2020, 13, 4093. [CrossRef] [PubMed]

40. Tomal, W.; Chachaj-Brekiesz, A.; Popielarz, R.; Ortyl, J. Multifunctional biphenyl derivatives as photosensitisers in various types of photopolymerization processes, including IPN formation, 3D printing of photocurable multiwalled carbon nanotubes (MWCNTs) fluorescent composites. RSC Adv. 2020, 10, 32162-32182. [CrossRef]

41. Tomal, W.; Pilch, M.; Chachaj-Brekiesz, A.; Galek, M.; Morlet-Savary, F.; Graff, B.; Dietlin, C.; Lalevée, J.; Ortyl, J. Photoinitiatorcatalyst systems based on meta-terphenyl derivatives as photosensitisers of iodonium and thianthrenium salts for visible photopolymerization in 3D printing processes. Polym. Chem. 2020, 11, 4604-4621. [CrossRef]

42. Orzeł, A.; Podsiadły, R.; Podemska, K.; Strzelczyk, R.; Kolińska, J.; Sokołowska, J. Dyes based on the 6,7-dichloro-5,8quinolinedione skeleton as new type II photoinitiators for radical polymerisation. Color. Technol. 2014, 130, 185-190. [CrossRef]

43. Podemska, K.; Podsiadly, R.; Orzeł, A.; Kowalska, A.; Maruszewska, A.; Marcinek, A.; Sokolowska, J. 6-Pyridinium benzo[a]phenazine-5-oxide derivatives as visible photosensitisers for polymerisation. Color. Technol. 2014, 130, $250-259$. [CrossRef]

44. Xiao, P.; Zhang, J.; Dumur, F.; Tehfe, M.A.; Morlet-Savary, F.; Graff, B.; Gigmes, D.; Fouassier, J.P.; Lalevée, J. Visible light sensitive photoinitiating systems: Recent progress in cationic and radical photopolymerization reactions under soft conditions. Prog. Polym. Sci. 2015, 41, 32-66. [CrossRef]

45. Hinsberg, O. Ueber Chinoxalinbasen. Eur. J. Org. Chem. 1887, 237, 327-372. [CrossRef]

46. Go, A.; Lee, G.; Kim, J.; Bae, S.; Lee, B.M.; Kim, B.H. One-pot synthesis of quinoxalines from reductive coupling of 2-nitroanilines and 1,2-diketones using indium. Tetrahedron 2015, 71, 1215-1226. [CrossRef]

47. Zhang, K.; Dai, Y.; Zhang, X.; Xiao, Y. Synthesis and photophysical properties of three ladder-type chromophores with large and rigid conjugation structures. Dye. Pigment. 2014, 102, 1-5. [CrossRef] 
48. Carlier, L.; Baron, M.; Chamayou, A.; Couarraze, G. Use of co-grinding as a solvent-free solid state method to synthesize dibenzophenazines. Tetrahedron Lett. 2011, 52, 4686-4689. [CrossRef]

49. Kumbhar, A.; Kamble, S.; Barge, M.; Rashinkar, G.; Salunkhe, R. Brönsted acid hydrotrope combined catalyst for environmentally benign synthesis of quinoxalines and pyrido[2,3-b]pyrazines in aqueous medium. Tetrahedron Lett. 2012, 53, 2756-2760. [CrossRef]

50. Zhang, L.; Zuo, Q. A series of blue-green-yellow-red emitting $\mathrm{Cu}(\mathrm{I})$ complexes: Molecular structure and photophysical performance. Spectrochim. Acta Part A 2019, 223, 117280. [CrossRef]

51. Einat, M.; Nagler, A.; Lishner, M.; Amiel, A.; Yarkoni, S.; Rudi, A.; Gellerman, G.; Kashman, Y.; Fabian, I. Potent antileukemic activity of the novel agents norsegoline and dibezine. Clin. Cancer Res. 1995, 1, 823-829. [PubMed]

52. Hussain, H.; Specht, S.; Sarite, S.R.; Saeftel, M.; Hoerauf, A.; Schulz, B.; Krohn, K. A New Class of Phenazines with Activity against a Chloroquine ResistantPlasmodium falciparumStrain and Antimicrobial Activity. J. Med. Chem. 2011, 54, $4913-4917$. [CrossRef]

53. Chen, J.; Chen, Y.; Wu, Y.; Wang, X.; Yu, Z.; Xiao, L.; Liu, Y.; Tian, H.; Yao, J.; Fu, H. Modulated emission from dark triplet excitons in aza-acene compounds: Fluorescence versus phosphorescence. New J. Chem. 2017, 41, 1864-1871. [CrossRef]

54. Mamada, M.; Perez-Bolivar, C.; Kumaki, D.; Esipenko, N.A.; Tokito, S.; Anzenbacher, P. Benzimidazole Derivatives: Synthesis, Physical Properties, and n-Type Semiconducting Properties. Chem. A Eur. J. 2014, 20, 11835-11846. [CrossRef]

55. Zhou, C.; Zhang, X.; Pan, G.; Tian, X.; Xiao, S.; Liu, H.; Zhang, S.; Yang, B. Investigation on excited-state properties and electroluminescence performance of Donor-Acceptor materials based on quinoxaline derivatives. Org. Electron. 2019, 75, 105414. [CrossRef]

56. Patil, M.U.; Shinde, S.K.; Patil, S.P.; Patil, S.S. [BBSA-DBN][HSO4]: A novel-SO3H functionalized Bronsted acidic ionic liquid for easy access of quinoxalines. Res. Chem. Intermed. 2020, 46, 4923-4938. [CrossRef]

57. Sahoo, P.K.; Giri, C.; Haldar, T.S.; Puttreddy, R.; Rissanen, K.; Mal, P. Mechanochemical Synthesis, Photophysical Properties, and X-ray Structures of N-Heteroacenes. Eur. J. Org. Chem. 2016, 2016, 1283-1291. [CrossRef]

58. Turner, H.S. 482. The formation of isomeric azo-compounds in the coupling of diazonium salts with 1-naphthylamine. J. Chem. Soc. 1949, 10, 2282-2289. [CrossRef]

59. Ōtani, S.; Watanabe, S.; Ogino, H.; Iijima, K.; Koitabashi, T. High Modulus Carbon Fibers from Pitch Materials. Bull. Chem. Soc. Jpn. 1972, 45, 3710-3714. [CrossRef]

60. VanAllan, J.A.; Adel, R.E.; Reynolds, G.A. Polynuclear Heterocycles. II. Addition Reactions of Benzophenazines. J. Org. Chem. 1962, 27, 2873-2878. [CrossRef]

61. Roy, N.; Sen, U.; Chaudhuri, S.R.; Muthukumar, V.; Moharana, P.; Paira, P.; Bose, B.; Gauthaman, A.; Moorthy, A. Mitochondria specific highly cytoselective iridium(iii)-Cp* dipyridophenazine (dppz) complexes as cancer cell imaging agents. Dalton Trans. 2021, 50, 2268-2283. [CrossRef]

62. Brouwer, A.M. Standards for photoluminescence quantum yield measurements in solution (IUPAC Technical Report). Pure Appl. Chem. 2011, 83, 2213-2228. [CrossRef]

63. Olmsted, J. Calorimetric determinations of absolute fluorescence quantum yields. J. Phys. Chem. 1979, 83, 2581-2584. [CrossRef]

64. Lament, B.; Karpiuk, J.; Waluk, J. Determination of triplet formation efficiency from kinetic profiles of the ground state recovery. Photochem. Photobiol. Sci. 2003, 2, 267-272. [CrossRef] [PubMed]

65. Monroe, B.M.; Weiner, S.A. Mechanisms of photochemical reactions in solution. LVIII. Photoreduction of camphorquinone. J. Am. Chem. Soc. 1969, 91, 450-456. [CrossRef]

66. Pyszka, I.; Kucybała, Z.; Paczkowski, J. Reinvestigation of the Mechanism of the Free Radical Polymerization Photoinitiation Process by Camphorquinone-Coinitiator Systems: New Results. Macromol. Chem. Phys. 2004, 205, 2371-2375. [CrossRef]

67. Pączkowski, J.; Pietrzak, M.; Kucybała, Z. Generalization of the Kinetic Scheme for Photoinduced Polymerization via an Intermolecular Electron Transfer Process. 2. Application of the Marcus Theory. Macromolecules 1996, 29, 5057-5064. [CrossRef]

68. Paczkowski, J.; Kucybala, Z. Generalization of the Kinetic Scheme for a Dye-Photosensitized Free-Radical Polymerization Initiating System via an Intermolecular Electron-Transfer Process. Application of Marcus Theory. Macromolecules 1995, 28, 269-273. [CrossRef]

69. Pyszka, I.; Jędrzejewska, B.; Kucybala, Z. Modified dibenzophenazine structures as photoinitiators for radical polymerization of trimethylolpropane triacrylate: The effect of the number of nitrogen atoms in the structure. Przemyst Chem. 2020, 99, 1605-1609. [CrossRef]

70. Pyszka, I.; Jędrzejewska, B.; Kucybala, Z. Phenazine derivatives as dye photoinitiators of radical polymerization of trimethylolpropane triacrylate: Impact of quantum yield of triplet state formation on photoinitiation efficiency. Przemyst Chem. 2020, 99, 691-695. [CrossRef]

71. Pyszka, I.; Kucybala, Z. Benzo- and dibenzoderivatives of phenazine as dye photoinitiators of radical polymerization of trimethylolpropane triacrylate: The substituent effect in the photoredox pair. Przemyst Chem. 2019, 98, 1290-1294. [CrossRef] 